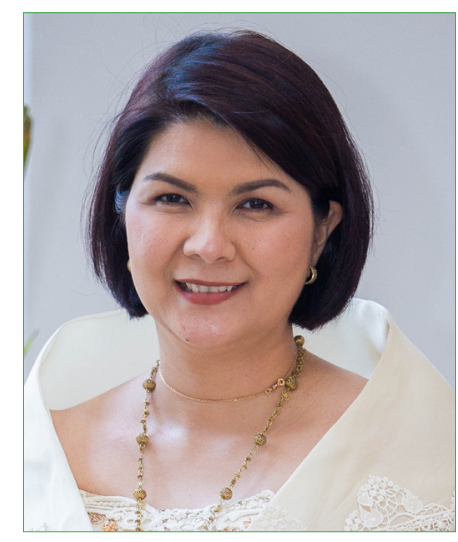

\title{
Why Research and Publish?
}

We have different reasons for publishing research. I can imagine the resident begrudging that without it, training would have been for naught. Then there are those rare individuals with whom the prospect of interesting research gives an inordinate sense of excitement. Many a time we say, "I've seen a case just like that" or "we've been doing that for a very long time". But if it is not written, who can say that it happened?

Why research and publish?

Knowledge for the love of knowing. Basic research often pursues questions that may have no clear application yet. But there is always promise it will make sense in the future. These little bits of information have, in many instances, come together into a bigger "aha" moment later on.

Answer a question --- understand how, what, when, why. Every single day, we ask something that there is no clear answer to. Be it in the course of seeing patients in the clinic, doing surgery or in moments of quiet introspection. Each candid query has potential to be a developed into a valid and rational research question.

Share knowledge. The Philippine clinical environment is unique. Patient profiles, conditions and treatments may vary from those reported elsewhere. That new case unseen or rarely reported in literature will be lost to memory without publication. Sharing it as published scientific literature ensures that the information will be preserved and may be of use to others in the future.

Intellectual and academic impetus. Residents take heart. Consultants in academic institutions also have this requirement. "Publish or perish" is taken seriously in the academe. This push from teaching institutions hopefully results in amplified output to sustain both the professor's needs and the medical community at large.

There are certainly more reasons. Which one is yours?

Why in the PJO-HNS?

We absorb information from all over the world and incorporate it into the daily grind of medical practice. But conditions by which Philippine ORL-HNS thrives is rife with its own special set of questions, answers, creative solutions, insight and the occasional surprise revelation. We have as much to share to the ORL-HNS community as the world has shared with us. The PJO-HNS, under the stewardship of Dr. Jose Florencio Lapeña, has achieved much in terms of ensuring that the researches it publishes gains international recognition with enhanced online accessibility. Thus, what is published in PJO-HNS will be searchable online and is linked within a system that allows ease of searching, citation and linking. Once it is written, published and uploaded, the information shared will never be lost or relegated to mere anecdotes.

There is much work to be done to further Philippine ORL-HNS research. As leaders of our specialty, the PSO-HNS enjoins all Fellows to foster that inquisitive spirit, search for answers and share this knowledge through the PJO-HNS. May this volume inspire you to contribute to this effort.

Mabuhay ang PJO-HNS! Mabuhay ang PSO-HNS!

AGNES T. REMULLA, MD

Philippine Society of Otolaryngology-Head and Neck Surgery 